\title{
An Insight into Nano Silver Fluoride-Coated Silk Fibroin Bioinspired Membrane Properties for Guided Tissue Regeneration
}

\author{
Aditi Pandey ${ }^{1, \dagger}{ }^{\dagger}$ Tzu-Sen Yang ${ }^{2,+}$, Ta-I Yang ${ }^{3}$, Wendimi Fatimata Belem ${ }^{4}$, Nai-Chia Teng $\left.{ }^{5}{ }^{(}\right)$, I-Wen Chen ${ }^{5}$, \\ Ching-Shuan Huang ${ }^{5}$, Aivaras Kareiva ${ }^{6}(\mathbb{D})$ and Jen-Chang Yang $1,5,7,8, *$ (D) \\ 1 Graduate Institute of Nanomedicine and Medical Engineering, College of Biomedical Engineering, \\ Taipei Medical University, Taipei 11052, Taiwan; aditi8293@tmu.edu.tw \\ 2 Graduate Institute of Biomedical Optomechatronics, Taipei Medical University, Taipei 11031, Taiwan; \\ tsyang@tmu.edu.tw \\ 3 Department of Chemical Engineering, Chung-Yuan Christian University, Taoyuan 32023, Taiwan; \\ taiyangyang@gmail.com \\ 4 International Ph.D. Program in Biomedical Engineering, College of Biomedical Engineering, \\ Taipei Medical University, Taipei 11031, Taiwan; belemfatimataw@gmail.com \\ 5 School of Dentistry, College of Oral Medicine, Taipei Medical University, Taipei 11052, Taiwan; \\ tengnaichia@hotmail.com (N.-C.T.); fatima777@tmu.edu.tw (I.-W.C.); jollyhuangtw12@gmail.com (C.-S.H.) \\ 6 Institute of Chemistry, Vilnius University, Naugarduko 24, LT-03225 Vilnius, Lithuania; \\ aivaras.kareiva@chgf.vu.lt \\ 7 Research Center of Biomedical Device, Taipei Medical University, Taipei 11052, Taiwan \\ 8 Research Center of Digital Oral Science and Technology, Taipei Medical University, Taipei 11052, Taiwan \\ * Correspondence: Yang820065@tmu.edu.tw; Tel.: +886-2-2736-1661 (ext. 5124); Fax: +886-2-27362295 \\ + Tzu-Sen Yang and Aditi Pandey contributed equally to this work.
}

Citation: Pandey, A.; Yang, T.-S.; Yang, T.-I.; Belem, W.F.; Teng, N.-C.; Chen, I.-W.; Huang, C.-S.; Kareiva, A.; Yang, J.-C. An Insight into Nano Silver Fluoride-Coated Silk Fibroin Bioinspired Membrane Properties for Guided Tissue Regeneration. Polymers 2021, 13, 2659. https:// doi.org/10.3390/polym13162659

Academic Editor: Tao-Hsing Chen

Received: 16 July 2021

Accepted: 6 August 2021

Published: 10 August 2021

Publisher's Note: MDPI stays neutral with regard to jurisdictional claims in published maps and institutional affiliations.

Copyright: (c) 2021 by the authors Licensee MDPI, Basel, Switzerland. This article is an open access article distributed under the terms and conditions of the Creative Commons Attribution (CC BY) license (https:/ / creativecommons.org/licenses/by/ $4.0 /)$.
Abstract: The current work focuses on the development of a novel electrospun silk fibroin (SF) nonwoven mat as a GTR membrane with antibacterial, biomineralization and biocompatible properties. The $\gamma$-poly glutamic acid ( $\gamma$-PGA)-capped nano silver fluoride (NSF) and silver diamine fluoride (SDF) were first synthesized, which were dip-coated onto electrospun silk fibroin mats (NSF-SF and SDF-SF). UV-Vis spectroscopy and TEM depicted the formation of silver nanoparticles. NSF-SF and SDF-SF demonstrated antibacterial properties (against Porphyromonas gingivalis) with 3.1 and 6.7 folds higher relative to SF, respectively. Post-mineralization in simulated body fluid, the NSF-SF effectively promoted apatite precipitation $(\mathrm{Ca} / \mathrm{P} \sim 1.67)$, while the SDF-SF depicted deposition of silver nanoparticles, assessed by SEM-EDS. According to the FTIR-ATR deconvolution analysis, NSF-SF portrayed $\sim 75 \%$ estimated hydroxyapatite crystallinity index (CI), whereas pure SF and SDF-SF demonstrated $\sim 60 \%$. The biocompatibility of NSF-SF was $\sim 82 \%$ when compared to the control, while SDF-coated samples revealed in vitro cytotoxicity, further needing in vivo studies for a definite conclusion. Furthermore, the NSF-SF revealed the highest tensile strength of $0.32 \mathrm{~N} / \mathrm{mm}$ and $1.76 \%$ elongation at break. Therefore, it is substantiated that the novel bioactive and antibacterial NSF-SF membranes can serve as a potential candidate, shedding light on further in-depth analysis for GTR applications.

Keywords: nano silver fluoride; silver diamine fluoride; antibacterial efficacy; biomineralization; in vitro cytotoxicity

\section{Introduction}

Periodontitis, a chronic inflammatory disease, is a condition caused by microorganisms in the tissues supporting teeth, leading to progressive deterioration of ligament, alveolar bone, thereby forming a deep periodontal pocket and gingival recession $[1,2]$. Periodontium regeneration can be achieved by various clinical therapies opted for treating severe periodontitis lesions. Periodontal defect reconstruction via guided tissue regeneration (GTR) membranes is one of the successful surgical techniques to resist proliferating connective tissue from migrating into the defect site [3]. 
The component used for the construction of the membrane used for GTR is a vital aspect of its efficacy. Essentially, the membrane should fulfill the main designing criteria for GTR, such as biocompatibility, cell occlusion, spaciousness, clinical manageability, and tissue integration [4]. Regarding the membrane materials used, various examples include synthetic polymers such as polytetrafluoroethylene (PTFE), polylactic acid (PLA), polyglutamic acid (PGA), natural polymers such as collagen, chitosan, gelatin, etc. $[5,6]$. The resorbable materials offer the advantages over the non-resorbable membranes (such as PTFE, titanium mesh, etc. [3]) of no further surgical interventions to remove the membrane, and therefore are extensively used in different clinical situations [6]. A popularly used natural polymer, silk fibroin (SF; drug-loaded, alone or functionalized) has noteworthy mechanical properties, well-recognized biocompatibility, proteolytic degradability, minimum inflammatory reaction, and is cost-effective. Moreover, the efficacy of silk fibroin towards protein and cell response mimics the extracellular matrix collagen, through the production of nanofibers by the electrospinning process [7-9]. However, the disadvantage of the produced SF lies in its brittleness, which restricts its utilization for flexible membrane material $[10,11]$. Therefore, SF was blended or reinforced with other materials such as polyethylene oxide and chitosan [12] to achieve desired mechanical or biological properties. However, the intended material of use for this work, SF, lacks antibacterial property for biomedical applications, for which, SF was enriched/modified by the use of functional nanomaterials/carriers such as silver, chitosan, graphene, and graphene oxide [13-17].

The key to successful therapy involves the reduction/elimination of periodontal pathogens (anaerobic bacteria) from the deep periodontal pocket $[1,18]$. Bacteria such as Aggregatibacter actinomycetemcomitans and Porphyromonas gingivalis (P.gingivalis), occur in the sub-gingival plaque/biofilm [19]. Microbial contamination of the GTR surgical sites may impact the cellular attachment process for periodontal ligament [20,21] and jeopardize the outcome of treatment, in terms of a hindrance towards the connective tissue/bone formation [22]. It was observed that introduction of antibiotics such as amoxicillin or tetracycline onto the membranes greatly reduced the bacterial adhesion [23]. Silver nanoparticles (AgNPs), developed by various techniques, result in higher anti-microbial activity in treating infections (due to unique chemistry, shape, and higher surface area) [24,25]. In tackling the infection, their applications include endodontics, dental, bone implantology and prostheses, and GTR [24,26-29]. The effect of AgNP-GTR has even been compared with the doxycycline (DOX-GTR) and found to be effective against several bacteria associated [29]. Silver diamine fluoride (SDF) and nano silver fluoride (NSF) are amongst the effective antibacterial agents used for treating dental caries [30,31]. Furthermore, fluoride also promotes remineralization. The efficacy of nano-silver constituting the fluoride inclusion was considered equivalent to that of SDF, with an added advantage of lower cytotoxicity than the SDF [30]. It is also suggested that the efficacy of NSF may be better than conventional fluorides regarding the treatment of caries lesion owing to the antibacterial action and remineralization [32]. If indicated, there may be a need for a material acting as a source of calcium or enhancing mineralization and aiding particle retention in the early process of GTR, which may also help engineer new periodontium, while restricting the gingival growth. The fabrication of such a kind of functional periodontal membrane by the electrospinning technique may act as an implant/interface between tissue and bone [33-35].

To date, no work has been reported for the application of NSF/SDF-coated materials in the field of guided tissue regeneration. Therefore, considering these facts, this work aims for the development of an NSF-coated electrospun SF and compared it with SDF-SF. The coated-SF materials are believed to act as an efficient antibacterial material. Moreover, this material may supposedly enhance tissue regeneration under the biomineralization process and possess efficient mechanical properties. 


\section{Materials and Methods}

\subsection{Materials}

Starting powders, silver nitrate (99.85); sodium borohydride (98+\%); ammonium fluoride (96\%); ammonia water ( $25 \%$ ); sodium carbonate (99\%); anhydrous lithium bromide (99\%); ammonium persulfate (98\%); aniline monomer (99\%); formic acid (98\%); and Bombyx mori silkworm cocoon were used as received without further purification. All reagents were obtained from Sigma-Aldrich, New Taipei City, Taiwan.

\subsection{Preparation of Degummed Silk Fibroin}

Native silkworm (Bombyx mori) silk comprises dual silk fibroin fibers coated with sericin. The sericin was removed by a degumming process, which implies boiling the silkworm cocoons in $0.02 \mathrm{M}$ sodium carbonate solution, for $30 \mathrm{~min}$. Subsequently, the dried degummed silk fibers were dissolved in a $9.3 \mathrm{M}$ lithium bromide solution for $4 \mathrm{~h}$ at $60^{\circ} \mathrm{C}$. The resultant fibroin solution was dialyzed using a dialysis cassette with 3500-MW cutoff (MWCO) for $72 \mathrm{~h}$, and then lyophilized for long-term storage.

\subsection{Preparation of Silk Fibroin Nanofiber Mats}

Silk fibroin nanofiber mats were prepared by using an electrospinning apparatus detail reported elsewhere [36]. The formic acid was utilized to prepare $10 \mathrm{wt} \%$ silk fibroin solutions. Subsequently, the resulting solution was ejected through a syringe with a needle size of gauge 20 . The feeding rate, applied voltage, and tip-target distance for electrospinning were $0.15 \mathrm{~mL} / \mathrm{hr}, 18 \mathrm{kV}$, and $12 \mathrm{~cm}$, respectively. The fabricated electrospun SF mats were treated with $90 \%$ ethanol, overnight, and then air-dried.

\subsection{Synthesis of NSF and SDF, and Their Coating on SF}

The AgNPs were synthesized by the reduction reaction of silver nitrate $\left(\mathrm{AgNO}_{3}\right)$ using sodium borohydride $\left(\mathrm{NaBH}_{4}\right)$ and $\gamma$-PGA as a capping agent [30]. Typically, we homogenized $\mathrm{AgNO}_{3}(1 \mathrm{~mL}, 0.11 \mathrm{M})$ and $\gamma$-PGA $(27.5 \mathrm{~mL}, 1.7 \mathrm{mM})$, initially dissolved in de-ionized water (DI) water, under magnetic stirring. Then, the mixture was subjected to drop-wise addition of freshly prepared $\mathrm{NaBH}_{4}(0.5 \mathrm{~mL}, 0.3 \mathrm{M})$, while stirring vigorously. $\mathrm{The} \mathrm{Ag}^{+}$ion reduction was triggered, and there was a change in the color of solution from colorless to reddish brown. Ammonium fluoride $\left(\mathrm{NH}_{4} \mathrm{~F}\right)(1 \mathrm{~mL}, 0.21 \mathrm{M})$ was added, under constant stirring, overnight. The synthesized solution was 1\% NSF (represented as NSF throughout the manuscript), a dark brown colored solution, which was stored at $4{ }^{\circ} \mathrm{C}$ in the refrigerator in a bottle covered with black plastic. The UV-Visible spectroscopy (JASCO V-770 Spectrophotometer, Tokyo, Japan) was then performed for the confirmation of the formation of AgNPs, and the size was estimated by transmission electron microscopy (TEM HT7700, HITACHI, Tokyo, Japan).

The $38 \%$ SDF was prepared by adding $6.8 \mathrm{~g}$ of $\mathrm{AgNO}_{3}$ in $5 \mathrm{~mL}$ of DI water, mixed homogenously by vortexing. This was followed by $\mathrm{NH}_{4} \mathrm{~F}$ addition $(1.47 \mathrm{~g})$, and again homogenized. Then, ammonia was introduced to the solution and the final volume of $13.2 \mathrm{~mL}$ was reached with DI water, keeping $\mathrm{pH}$ 7. The colorless solution was stored in a bottle (wrapped with a black plastic) at $8{ }^{\circ} \mathrm{C}$ [37]. The $38 \%$ SDF (concentrated SDF, represented as CSDF) was also diluted to $1 \%$ SDF (diluted SDF, represented as DSDF), in order to have the same concentration as that of NSF (for comparison purposes).

The prepared NSF and SDF (CSDF, DSDF) were coated using the dip-coating process on the SF mats for a period of $24 \mathrm{~h}$ under dark conditions and then oven-dried and stored in the dark.

\subsection{Antibacterial Activity of the Coated SF}

The antibacterial property of the samples (SF, NSF, CSDF, DSDF-coated silk fibroin, $n=3$ ) was assessed using Gram-negative (P.gingivalis; ATCC 33277). In a typical experiment, the samples were introduced into a 24-well plate (in two sets), and $100 \mu \mathrm{L}$ of the bacterial solution ( 0.1 optical density, OD) was seeded upon samples. The samples were incubated 
under anaerobic conditions, for $48 \mathrm{~h}$, at $37^{\circ} \mathrm{C}$, after which, they were thoroughly rinsed with PBS to remove the non-adherent bacterial cells. One of the sets of the cultured samples was analyzed by SEM imaging for qualitative and morphological analysis. The adhered bacteria were fixed with glutaraldehyde and incubated at $4{ }^{\circ} \mathrm{C}$ overnight. After thorough washing with PBS, the samples were then dehydrated in a gradient alcohol series and sputter-coated with gold for scanning electron microscopy (SEM, SU3500, HITACHI, Tokyo, Japan) analysis. On the other set of cultured samples, the MTT analysis was carried out and the absorbance was measured at $570 \mathrm{~nm}$, for the quantitative assessment.

\subsection{Biomineralization Studies}

Simulated body fluid (SBF) was utilized as the immersion solution to perform the biomineralization process on the samples. The $10 \times$ SBF was prepared by Tas and Bhaduri method [38]. The chemicals and their sequence of mixing were according to Table 1, starting from $\mathrm{NaCl}$ and ending with $\mathrm{Na}_{2} \mathrm{HPO}_{4}$. Just before the biomineralization experiment was conducted, $\mathrm{NaHCO}_{3}$ was added to the solution and homogenized under constant stirring. The $10 \times$ SBF was stored at $4{ }^{\circ} \mathrm{C}$.

Table 1. Chemicals and their sequence of addition for the preparation of $10 \times \operatorname{SBF}(1 \mathrm{~L})$.

\begin{tabular}{ccc}
\hline Sequence & Chemicals & Weight (g) \\
\hline 1. & $\mathrm{NaCl}$ & 58.443 \\
2. & $\mathrm{KCl}$ & 0.373 \\
3. & $\mathrm{CaCl}_{2} \cdot 2 \mathrm{H}_{2} \mathrm{O}$ & 3.675 \\
4. & $\mathrm{MgCl}_{2} \cdot 6 \mathrm{H}_{2} \mathrm{O}$ & 1.016 \\
5. & $\mathrm{Na}_{2} \mathrm{HPO}_{4}$ & 1.199 \\
6. & $\mathrm{NaHCO}_{3}$ & 0.840 \\
\hline
\end{tabular}

The electrospun samples (SF, NSF, CSDF, DSDF-coated SF, $n=3$ ) were cut into $5 \times 5 \mathrm{~mm}$ pieces, placed in 24-well plates and soaked into the $10 \times \mathrm{SBF}$ for $24 \mathrm{~h}$ under continuous stirring. After this, they were oven-dried, gold-coated and subjected to microstructural and elemental characterization under SEM-EDS.

The chemical characterization of the formed apatite crystals on the samples was performed by the FTIR-ATR spectroscopy (Nicolet 6700, Thermo-Fisher-Nicolet Instruments, Madison, WI, USA, coupled by mercury-cadmium-telluride (MCT) detector and infrared synchrotron radiation as light source at BL14A1, National Synchrotron Radiation Research Center (NSRRC) Taiwan, for 128 scans, resolution of $4 \mathrm{~cm}^{-1}$, and compared with the FTIR spectra of the non-biomineralized original silk, and coated-silk samples. The spectra were deconvoluted and peak fitting was carried out using peak fit software (Peakfit v. 4.11, Systat Software, Inc., San Jose, CA, USA).

\subsection{Biocompatibility Studies of the Extracted Medium and SF-Based Samples}

The mouse fibroblasts cell line, L929 cell line (BCRC, RM60091, Bioresource Collection and Research Center, Hsinchu City, Taiwan). The cells were first expanded in Dulbecco's modified eagles medium with $10 \%$ FBS (Gibco 10082147, ThermoFisher, Tokyo, Japan) and $3 \mu \mathrm{g} / \mathrm{mL}$ geneticin (G418, ThermoFisher, Tokyo, Japan) at $37^{\circ} \mathrm{C}$ in a $95 \%$ humidity and $5 \%$ $\mathrm{CO}_{2}$ incubator.

In a typical experiment, following a modified protocol of ISO10993-5 method [39], $1 \times 10^{6}$ cells $/ \mathrm{mL}$ cells were incubated with extract of specimens $(n=3,5 \times 5 \mathrm{~mm}$, earlier incubated for $72 \mathrm{~h}$ at $37^{\circ} \mathrm{C}$ for extraction process), in 24 well culture plate and allowed to incubate for $24 \mathrm{~h}$. Then, the medium was removed, and the wells were rinsed with phosphate buffer saline (PBS). In order to determine the cell viability (through the metabolic activity determination), MTT assay (MTT: (3(4, 5-dimethylthiazol-2-yl)-2,5-diphenyl tetrazolium bromide)) (Sigma Aldrich, St. Louis, MO, USA), was performed, for the quantitative estimation. MTT: PBS (1:10 ratio) was then added to each well, and incubated for $4 \mathrm{~h}$, after which dimethyl sulphoxide (DSMO) was added to the wells, thereby dissolving the 
formazan crystals to develop a purple color. The absorbance of the formed, purple-colored solution was read at $570 \mathrm{~nm}$, by a microplate reader.

\subsection{Mechanical Property Measurements}

Tensile tests of the electrospun SF-based samples (dimension of $30 \times 10 \mathrm{~mm}$ ) were carried out with a TA.XT plus Texture Analyser, Texture Technologies, Hamilton, MA, USA, with a $50-\mathrm{N}$ load cell, at a strain rate of $10 \mathrm{~mm} / \mathrm{min}$. The samples were mounted vertically between the gripping units of the mechanical testing apparatus, with a gauge length of $20 \mathrm{~mm}$ for mechanical loading. Due to the porous nature of nonwoven, we were not able to have the exact area of the cross-section to have the value of force/area (F/A). Therefore, instead of F/A, we can use the F/width (N/10 mm) [40].

\subsection{Statistical Analysis}

The experiments were in triplicates, with mean \pm standard deviation calculation, and statistical significance determination by Student's $T$-test $(p<0.05)$.

\section{Results and Discussions}

\subsection{Characterization of the Silver Nanoparticles}

The UV-Vis absorption spectra of the AgNPs (NSF) is represented in Figure 1a. The characteristic peak at $403 \mathrm{~nm}$ depicts the formation of $\mathrm{AgNPs}$ from $\mathrm{AgNO}_{3}$ (in the presence of $\gamma$-PGA) upon addition of $\mathrm{NaBH}_{4}$, indicating reduction of $\mathrm{Ag}^{+}$ions to $\mathrm{Ag}^{0}$, which shows the characterization of the synthesized AgNPs. The TEM micrographs in Figure $1 \mathrm{~b}$ reveals nano-sized spherical particles, ranging in between $3-6 \mathrm{~nm}$, and capped by $\gamma$-PGA.
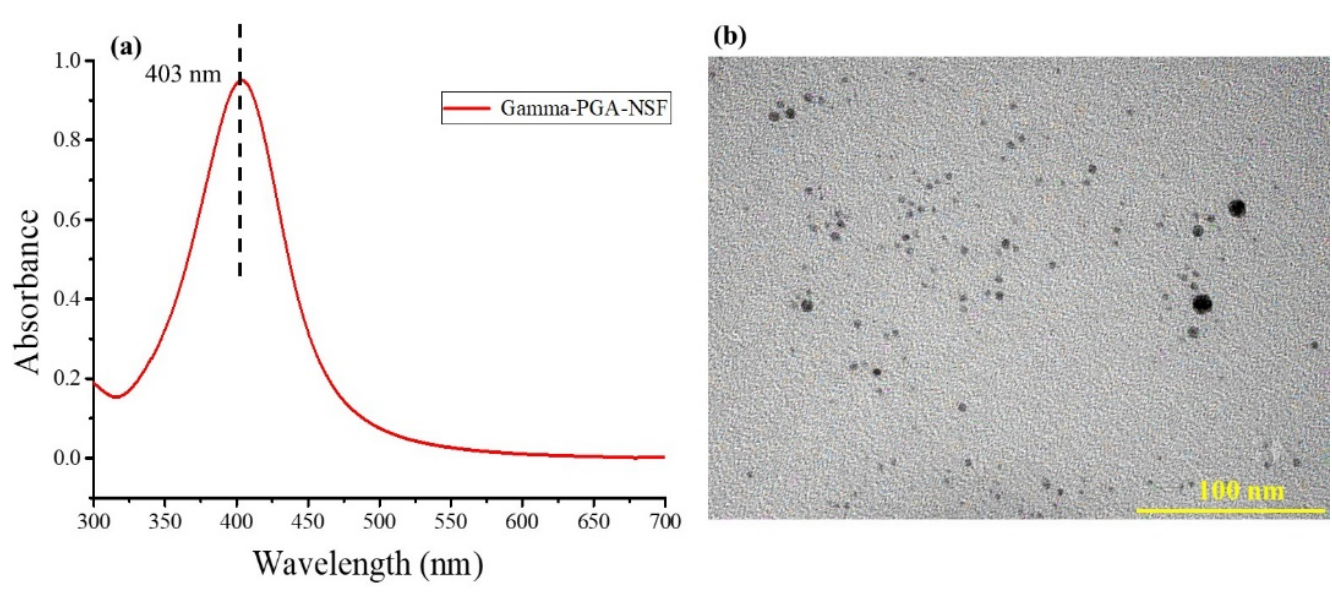

Figure 1. (a) UV-Vis spectra and (b) TEM image of the synthesized NSF.

The current work involved the development of polyelectrolyte-based (involving electrostatic interactions with positive silver ions) formulation, comprising of nano silver fluoride, NSF. As reported, chitosan as a carrier was used for the NSF synthesis because of its ability to form complex interactions with AgNPs [30] and proteins [41], thereby increasing muco-adhesion. However, the $\gamma$-PGA used as an anionic polyelectrolyte is assumed to interact electrostatically with the cationic Ag ions, thereby forming a stable complex.

\subsection{Microstructural and Chemical Characterization of Uncoated and Coated SF}

The colloidal AgNPs (NSF) and the elemental silver in SDF, after preparation, were subsequently coated on electrospun SF webs, by overnight coating and then drying. The AgNPs on SF were detected and confirmed by their morphological investigations through SEM. Figure 2 represents SEM images of uncoated SF, and elemental Ag and AgNPs coated $\mathrm{SF}$ (indicated by yellow arrows). The nonwoven electrospun nanofibres were reported for preventing the cell infiltration, leading to occlusion, without depleting oxygen and nutrients, thus justifying the role of electrospinning as a promising method for developing 
physical barrier. The NSF/SDF coated SF shows uniform distribution on the coated electrospun fiber mats [42]. It is suggested that the high surface free energy of silver nanoparticles, which leads to their instability, causes migration and aggregation of silver nanoparticles [43].
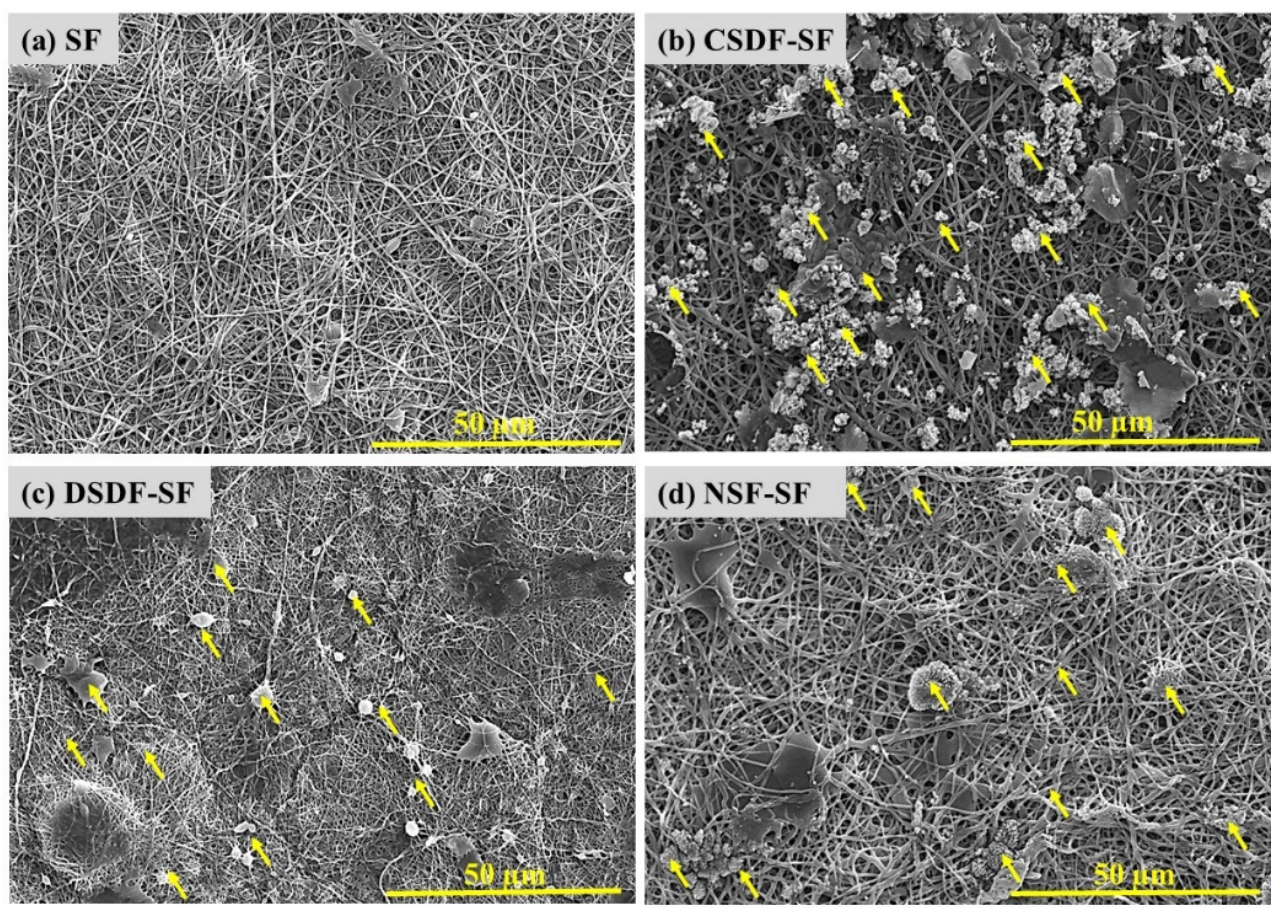

Figure 2. Scanning electron micrographs of uncoated and coated electrospun SF membranes, yellow arrows represent $\mathrm{Ag}$ deposition.

\subsection{Antibacterial Efficacy Evaluation of SF-Based Samples}

A Gram-negative and pathogenic bacteria P.gingivalis, occurring in the sub-gingival plaque/biofilm, was utilized to examine the antibacterial activity of silk-based membranes. The intertwined membranes after their immersion into bacterial suspension for $24 \mathrm{~h}$, gave rise to P.gingivalis adhesion and growth onto the surface, as presented in the SEM images in Figure 3a-e. There is no adhesion of bacteria on the pure SF only when immersed in the medium without bacteria (only medium and SF, MS), portraying no microbial contamination of the medium. Further, upon exposing the uncoated SF to P.gingivalis broth, the membrane surface (medium with silk fibroin and bacteria, MSB) is densely covered by bacterial cells. On the other hand, the CSDF-SF sample shows negligible bacterial adhesion. However, when diluted or 1\% SDF was exposed to the bacteria, it can be observed that the lowered silver content in DSDF samples apparently may not be enough to act against the bacteria, leading to increased bacterial adhesion than that on CSDF-SF, however lower than that on the pure SF sample. The NSF-SF sample displays effectively lower bacterial density when compared to SF and DSDF matrices, although not as much as the CSDF-coated matrix. 

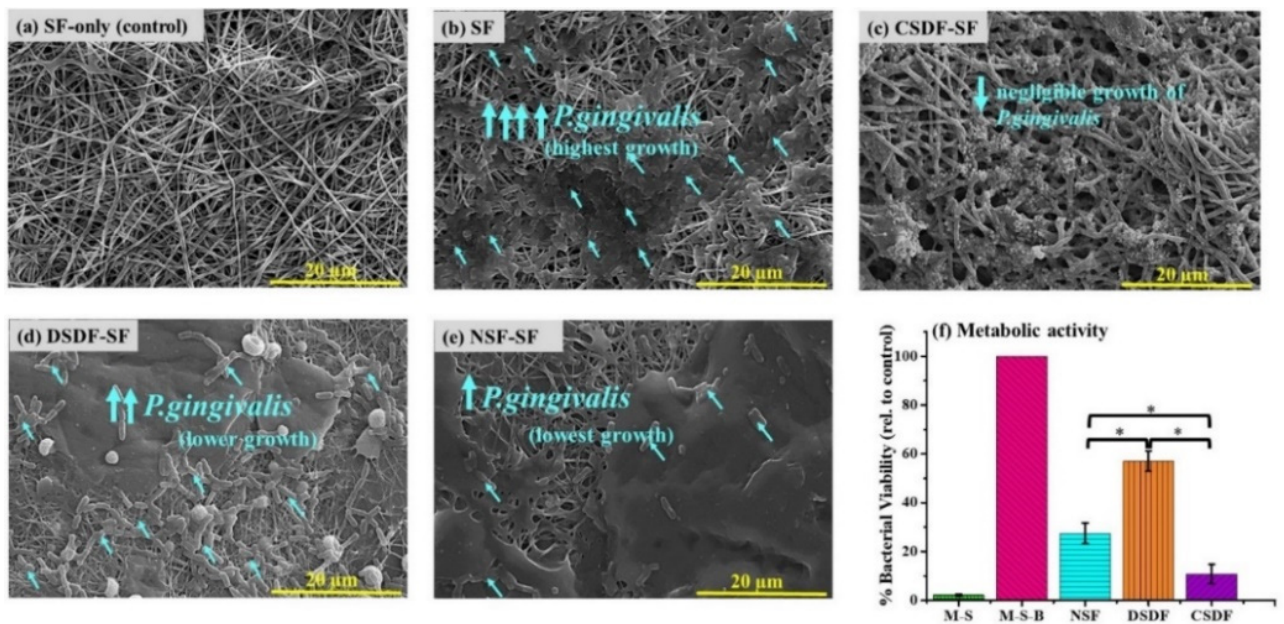

Figure 3. (a-e) SEM images showing the bacterial adhesion on the SF-based samples, and (f) the quantitative estimation of the metabolic activity by MTT assay ( ${ }^{*}$ depicts $p$-value $\left.<0.05\right)$.

The metabolic activity (hence the bacterial viability) of the P.gingivalis bacteria on the electrospun silk fibroin-based samples (wherein the coated SF samples are denoted as CSDF, DSDF, and NSF) as assessed by the MTT assay (Figure 3f), is found to be in the same trend corresponding to the SEM images. The highest bacterial viability is on the SF sample immersed in bacterial broth, which is considered to be $100 \%$. From these findings it can be noted that the $38 \%$ SDF coated sample (CSDF) is found to inhibit maximum bacterial growth (6.7 folds lower than SF), attributing to its highest silver content. However, the NSFSF sample is also found to be a potential material controlling the P.gingivalis adhesion, as portrayed by the significantly lower bacterial density of 3.1 and 1.9 folds, when compared to SF and DSDF (1.6 folds lower than SF), respectively, yet 2.1 folds significantly higher density relative to CSDF.

Apart from the role of SDF as a popular anti-caries agent [44], as recently reported by Rams et al., 38\% and 19\% of SDF considerably inhibited in vitro activity of sub-gingival pathogens extracted from severe periodontitis lesions, suggesting its potential in periodontal infection management [45]. The silver ions have a broad spectrum of antimicrobial activity. Their mode of action involves attacking the -SH groups of enzymes, obstructing the pathway of protein synthesis. These ions also denature the bacterial DNA, causing a bactericidal action, and were used as reinforcements/coatings [46-48]. Another widely used caries inhibiting formulation is NSF with antimicrobial activity similar to SDF, which has the advantage of its lower toxicity to eukaryotic cells on account of utilizing silver nanoparticles [30]. The AgNPs, when synthesized using an appropriate capping agent may be effective in controlling periodontal infections, with the added advantage of smaller size as a criterion for enhanced antibacterial action against oral anaerobic pathogens [49]. The GTR dressing coated with AgNPs leads to a reduction in bacterial adherence or penetration, which may aid in the treatment of intra-bony defects and clinical success [50,51].

\subsection{Effects of SBF on Coated and Uncoated Silk Observed by SEM-EDS and ATR-Spectroscopy}

The apatite deposition on the silk fibroin-based membrane was proceeded by immersing them into $10 \times$ SBF solution (for $24 \mathrm{~h}$ ) for the biomineralization process as shown by the SEM images (Figure 4a-d) and its corresponding elemental analysis spectra in (Figure $4 \mathrm{e}-\mathrm{h}$ ). The molar $\mathrm{Ca} / \mathrm{P}$ ratio of a porous and entangled matrix of pure SF ( 2.1), CSDF-coated $(<0.5,80 \% \mathrm{Ag}), \mathrm{DSDF}-$ coated $(<0.5,7.3 \% \mathrm{Ag})$ and NSF-coated SF $(\sim 1.67$, negligible Ag) following $24 \mathrm{~h}$ SBF immersion depicts high Ca and P deposition on pure SF and NSF-SF samples, while negligible $\mathrm{Ca}, \mathrm{P}$ and high Ag deposition on SDF-coated samples. Silver is less reactive than hydrogen and can hardly replace $\mathrm{H}^{+}$in a reaction. Thus $\mathrm{Ag}^{+}$is inclined to bind to a specific site of MMPs to inactivate their catalytic functions. The silver ions 
from SDF are also supposed to inhibit the metal metalloproteinase (MMP) and cathepsin, thereby preventing collagen degradation [52].
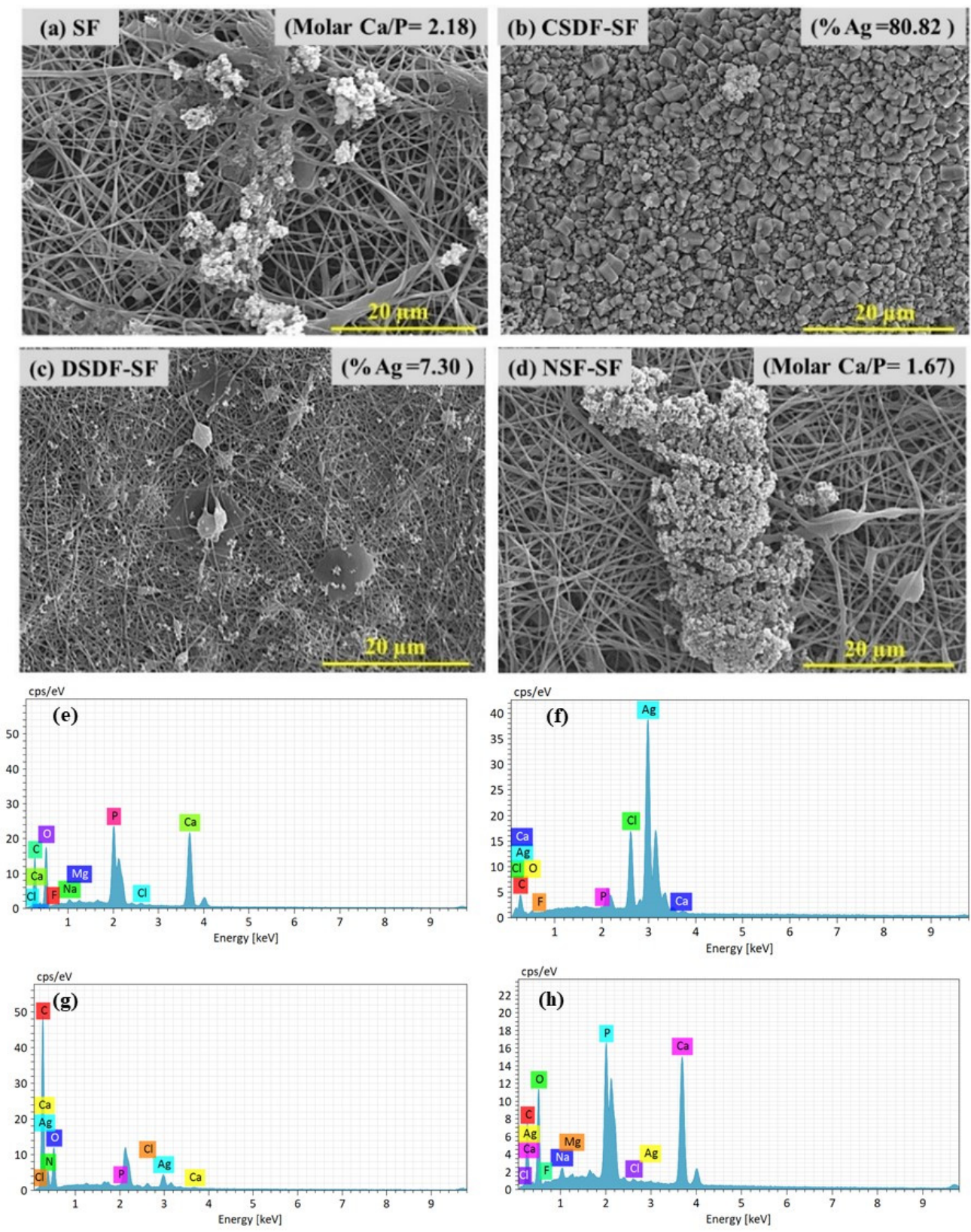

Figure 4. SEM images of biomineralized (a) SF, (b) CSDF-SF, (c) DSDF-SF, (d) NSF, and (e-h) their corresponding EDS spectra.

The $\mathrm{Ca} / \mathrm{P}$ ratio obtained for the $\mathrm{SF}$ sample, higher than the ideal molar ratio of $\mathrm{Ca} / \mathrm{P}$ of hydroxyapatite (1.67), and that for the NSF-SF membrane can also be seen by $\mathrm{Ca}, \mathrm{P}$, and $\mathrm{O}$ distribution in the elemental mapping images shown in Figure 5. The high $\mathrm{Ca} / \mathrm{P}$ ratio demonstrated calcium phosphate layer formation, resembling the mineral content of natural bone and verified the biomimetic apatite formation [53]. The SDF-treated samples present Ag deposition on the samples after biomineralization. The concentrated (38\%) and diluted ( $\sim 1 \%$ ) SDF-SF samples result in $\sim 80 \%$ and $\sim 7 \%$ precipitation of silver. The aggregation of $\mathrm{Ag}$ is in the same line with in vitro studies reported for the reaction of SDF with gelatin (as a collagen substitute) for deposition of metallic silver [54,55]. The hydroxyapatite crystal deposition on the $\gamma$-PGA NSF-SF possesses a molar Ca/P ratio 
of $\sim 1.67$. The high apatite deposition on this sample may be accredited to the effect of $\gamma$ PGA-capped NSF on the silk fibroin. The glutamic acid residues possess a negative charge, which attracts more $\mathrm{Ca}^{+}$ions from $\mathrm{SBF}$, thereby attracting the $\mathrm{PO}_{4}{ }^{-}$ions and enhance the supersaturation such that they develop into HAp crystals [56,57].
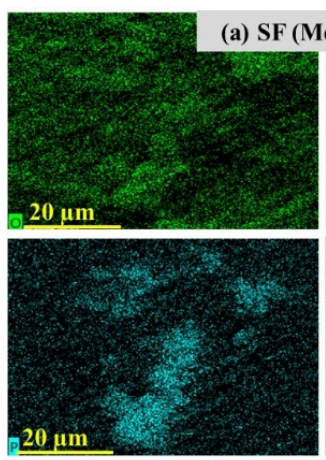
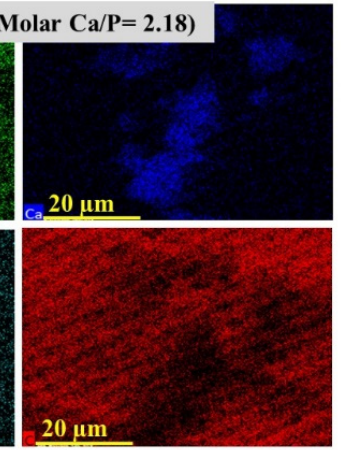
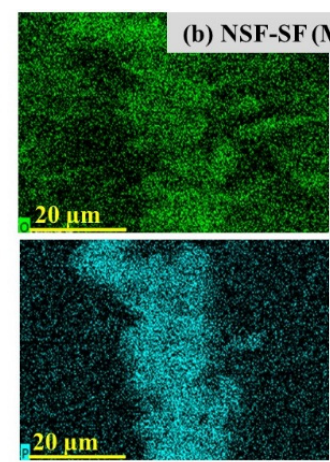

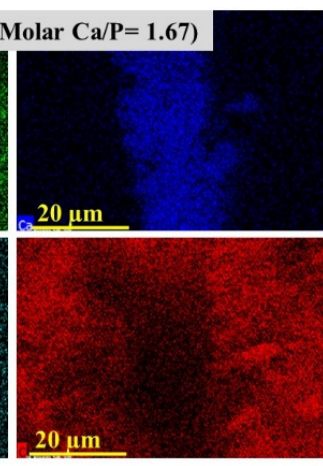

Figure 5. Elemental mapping showing the Ca (blue), $\mathrm{P}$ (turquoise), and $\mathrm{O}$ (green) distribution on biomineralized (a) SF and (b) NSF-SF.

Further, in order to analyze the chemical composition of the samples, FTIR-ATR spectroscopy was conducted. As shown in Figure 6, the ATR spectra of SF-based samples depict the apatite deposition in the form of characteristic HAp absorption peaks/bands observed at $\sim 1130 \mathrm{~cm}^{-1}$ specifically corresponding to the $\mathrm{P}-\mathrm{O}$ stretching of the $\mathrm{PO}_{4}[58,59]$. This peak is observed for all samples, SF, CSDF-SF, DSDF-SF, and NSF-SF. Furthermore, the additional distinctive peaks of $\mathrm{PO}_{4}$ are found to be appearing from $950-960 \mathrm{~cm}^{-1}$. The apatitic phase at $\sim 960 \mathrm{~cm}^{-1}$ relates to the $\gamma_{1}\left(\mathrm{PO}_{4}\right)$ of the HAp, which may be of lower intensity. Indeed, the $950 \mathrm{~cm}^{-1}$ peak portrays the amorphous calcium phosphate (ACP) formation [59].

The estimated HAp crystallinity index (CI) is estimated as the ratio of absorbance $\mathrm{A}_{960}$ to $\left(\mathrm{A}_{960}+\mathrm{A}_{950}\right)$, which is found to be a maximum of $\sim 75 \%$ for NSF-SF samples, depicting the highest crystalline apatite deposition corresponding to the SEM-EDS data. Further, the SF membranes elicit $\sim 60 \%$ estimated HAp CI, and as also observed through the SEM-EDS, the $\mathrm{Ca} / \mathrm{P}$ ratio was $\sim 2.1$, because of which there may be a possibility of the presence of ACP phase, which may not have completely transformed to HAp mineralization process, giving rise to the high $\mathrm{Ca} / \mathrm{P}$ ratio of $\mathrm{ACP}$ and HAp together. Noteworthy, in the case of CSDF-SF samples, there occurs $\sim 60 \%$ estimated HAp CI, which was not observed from the SEM-EDS. This difference in the inference may be possibly attributed to the masking effect of the silver ions $(\sim 80 \%)$ on the sample surface after the mineralization reactions. The effective biomimetic mineralization invoked post $10 \times$ SBF treatment suggests the possible boneregeneration platform (owing to bone-bonding potential and biocompatibility) offered by these electrospun SF-based constructs, with the highest estimated CI on NSF-SF [60-62].

The $\beta$-sheet content is assessed by the ratio of absorbance of $\beta$-sheet $\left(1265 \mathrm{~cm}^{-1}\right)$ to the sum total of absorbance of $\beta$-sheet $\left(1265 \mathrm{~cm}^{-1}\right)$ and of the random coil $\left(1235 \mathrm{~cm}^{-1}\right)$, as represented in Table 2, along with their full-width half maxima (FWHM). Figure S1 in supporting information represents the FTIR-ATR spectra of the SF-based samples before biomineralization. Table $\mathrm{S} 1$ shows the $\beta$-sheet/random coil ratio and their corresponding FWHM values. An enhancement by $\sim 1.7$ folds of the $\beta$-sheet proportion before and after mineralization for SF, and NSF-SF samples is revealed, while for the SDF-coated samples, there is barely a difference noted. 


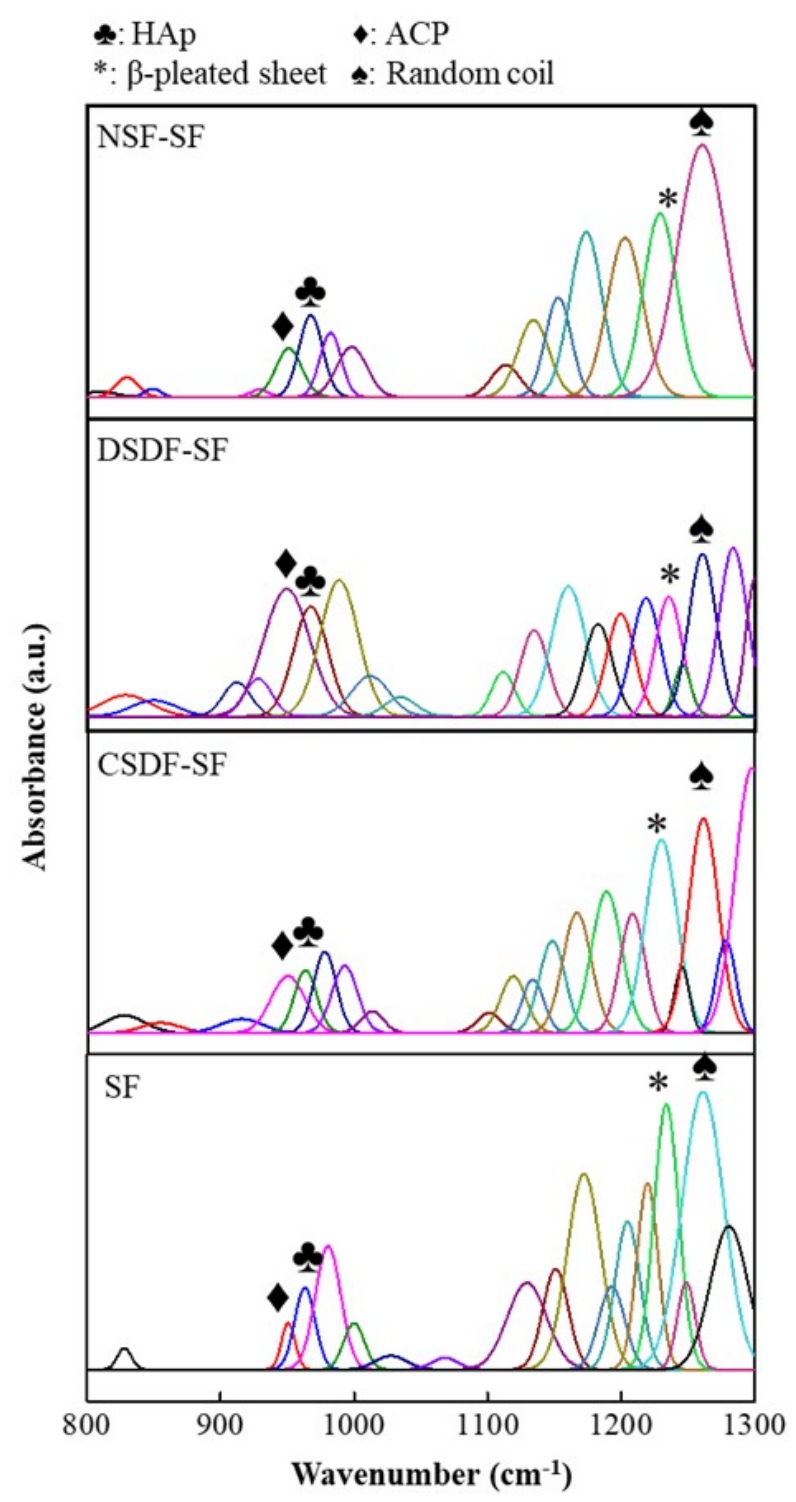

Figure 6. FTIR-ATR spectra of the silk-fibroin-based membranes after the biomineralization process in $10 \times$ SBF for $24 \mathrm{~h}$, showing the HAp and ACP peaks.

Table 2. Table for crystallinity index of HAp, silk fibroin, and its FWHM (unit: \%), in the SF-based biomineralized samples. ACP: $950 \mathrm{~cm}^{-1}$, HAp: $960 \mathrm{~cm}^{-1}$; random coil: $1235 \mathrm{~cm}^{-1}$ (amide III), $\beta$-sheet crystal: $1265 \mathrm{~cm}^{-1}$ (amide III).

\begin{tabular}{|c|c|c|c|c|c|c|}
\hline & $\frac{\mathbf{A}_{960}}{\mathbf{A}_{950}+\mathbf{A}_{960}}$ & $\frac{\mathbf{A}_{1265}}{\mathbf{A}_{1235}+\mathbf{A}_{1256}}$ & FWHM $\mathbf{A}_{950}$ & FWHM $\mathbf{A}_{960}$ & FWHM $\mathbf{A}_{1235}$ & FWHM $\mathbf{A}_{1265}$ \\
\hline SF & 60 & 53 & 12.02 & 17.89 & 21.88 & 36.93 \\
\hline NSF & 75 & 56 & 20.16 & 27.94 & 30.36 & 37.34 \\
\hline DSDF & 50 & 56 & 40.56 & 30.09 & 24.24 & 23.63 \\
\hline CSDF & 60 & 52 & 29.68 & 19.78 & 28.09 & 26.28 \\
\hline
\end{tabular}

\subsection{Response of Extracted Medium from the SF-Based Samples towards L929 Cell Line}

The cytotoxic properties of the membrane-extracted substrates are represented in Figure 7. It can be demonstrated that extract of SF $(90.15 \pm 7.02 \%)$ and NSF-SF $(78.06 \pm 4.00 \%)$ are not cytotoxic in comparison to the control group (comprising cells and medium only). On the contrary, the DSDF and CSDF-SF extracts elicit only $8.97 \pm 1.36 \%$ and $11.61 \pm 3.40 \%$ viable cells, respectively, thereby displaying a cytotoxic phenomenon. 


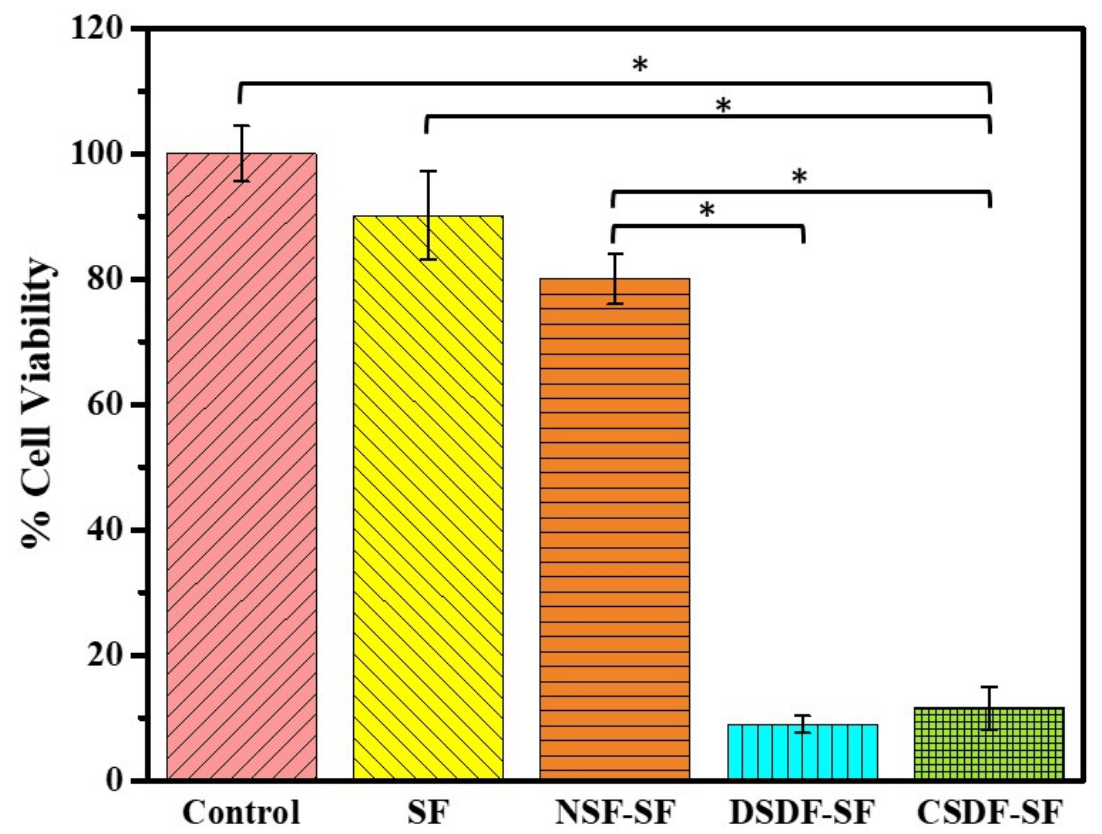

Figure 7. The cell viability of the extracted materials, examined through the MTT assay ${ }^{*}$ depicts $p$-value $<0.05)$.

An effective understanding of material-host interactions in terms of their biocompatibility is required for the functionality of a biomedical membrane. The excellent biocompatibility of natural silk-based materials has led to its increasing interest in medical purposes. Further, the silk fibroin (SF) gels, micro- and nanonets, sponges, films have the potential ability in therapeutic applications [63-65]. Therefore, the cellular response to a newly-developed NSF/SDF-coated SF barrier membrane was investigated using the L929 cell line. The cytotoxic effects of the extracts [66] from both the SDF-coated membranes could be justified by the role of Ag ions released during the 3-day pre-incubation of the membranes with the medium. The role of $0.01 \%$ SDF on human gingival fibroblasts triggered almost $100 \%$ cell death, depicting its potential cytotoxicity [67]. The SDF used in this study is $38 \%$ (CSDF) and 1\% (DSDF), which has a higher concentration of Ag, thereby releasing more silver ions into the medium after exposure of 3 days. This accounts for the SDF-induced cell death. However, the extracts from NSF-SF support the cell growth (almost like SF and control samples), despite the presence of nano silver. This could be plausibly attributed to the low concentration of Ag ions, which may have been released after the $72 \mathrm{~h}$ exposure time. Therefore, the DSDF and SDF-SF samples raise concerns regarding their in vitro cytotoxic properties. However, the long-term effects of the use of SDF in vivo are still required for further conclusive statements [67]. SDF has also been commonly used in the field of dentistry, which accounts for its no potential risks in humans, due to the combined action of several factors as mentioned before. According to this study, the NSF-SF membranes can be concluded to possess no deleterious effects or cytotoxicity against L929 and the biocompatibility of SF remains unchanged by the NSF-coating on it.

\subsection{Mechanical Property Analysis of the SF-Based Samples}

The tensile strength of the coated and uncoated SF samples is represented in the form of stress-strain curve in Figure 8. It can be observed that the tensile strength of SF samples is $0.22 \mathrm{~N} / \mathrm{mm}$, which increases upon addition of NSF by 1.47 folds. Meanwhile, the coating of DSDF and CSDF onto SF reduces the tensile strength to 0.09 and $0.02 \mathrm{~N} / \mathrm{mm}$, respectively. Similarly, the elongation at break, indicating the elasticity of the membrane is found to be highest for the NSF-SF (1.76\%), followed by SF (1.51\%), DSDF-SF $(0.67 \%)$, and CSDF-SF (0.99\%). 


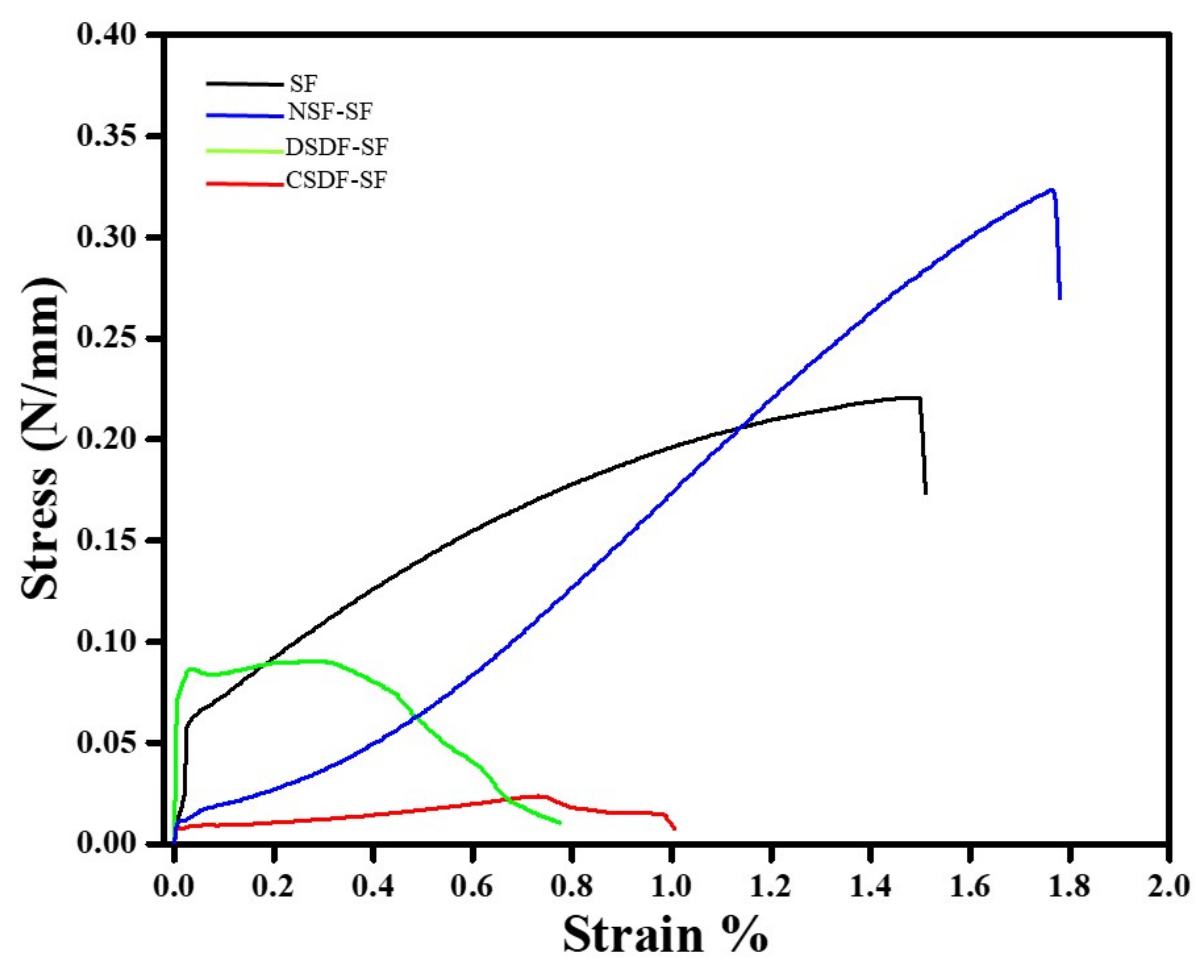

Figure 8. Stress-strain curves of uncoated and coated-SF samples.

Mechanical properties are an important criterion for determining the applications of materials. The variation in mechanical properties of materials should be compatible with the healing or regeneration process. The silk fibroins are characterized as natural polymers, with $\beta$-sheets or crystals responsible for stability and in turn the mechanical properties [68]. In electrospun silk fibroins (with higher mechanical properties), treated with ethanol, the $\beta$-sheet structure can be easily enhanced [68]. So is observed in our study, wherein the ethanol-treated SF which when further coated by various materials exhibited higher $\beta$-sheet content and crystallinity. The enhanced tensile strength of NSF-SF samples could be attributed to the higher crystallinity than the SF samples. This may also be accredited to the strong protective effect of low concentration of silver nanoparticles [69] (in NSF), distributed evenly throughout the SF matrix. This may help in the possible closure of the certain voids present in the membrane by the NSF particles, thus leading to the strong reinforcing effect by the AgNPs, inhibiting polymer drawing, and increasing the tensile strength. However, the lowered tensile strength of the CSDF and DSDF-SF samples, despite the higher crystallinity may be due to the high concentration of the silver ions in the DSDF and CSDF solutions, which likely led to the agglomeration and aggregation of $\mathrm{Ag}^{+}$ions onto the SF membranes. This, in turn, may lead to the stress concentration effect, thereby deteriorating the tensile strength of the samples [69]. Therefore, it can be concluded that the NSF-SF samples can be considered with the suitable balance between the mechanical properties, which may behave as an apt candidate for GTR applications, after in-depth analysis.

Scheme 1 represents the space making NSF-SF GTR membrane (and its required properties), placed at the affected area, (a) its fabrication (from electrospinning of silk fibroin to NSF dip coating on the SF membrane), subjected to in vitro studies, (b) antibacterial efficacy (against P.gingivalis), (c) bioactivity (mineralization in $10 \times$ SBF) analysis, (d) biocompatibility analysis (cytotoxicity study by reaction of MTT reagent with L929 cell), and (e) mechanical strength test (tensile stress and elongation at break). In this work, the effective antibacterial activity of NSF, comparable with SDF, against P.gingivalis speculates its budding potential in sub-gingival applications. 


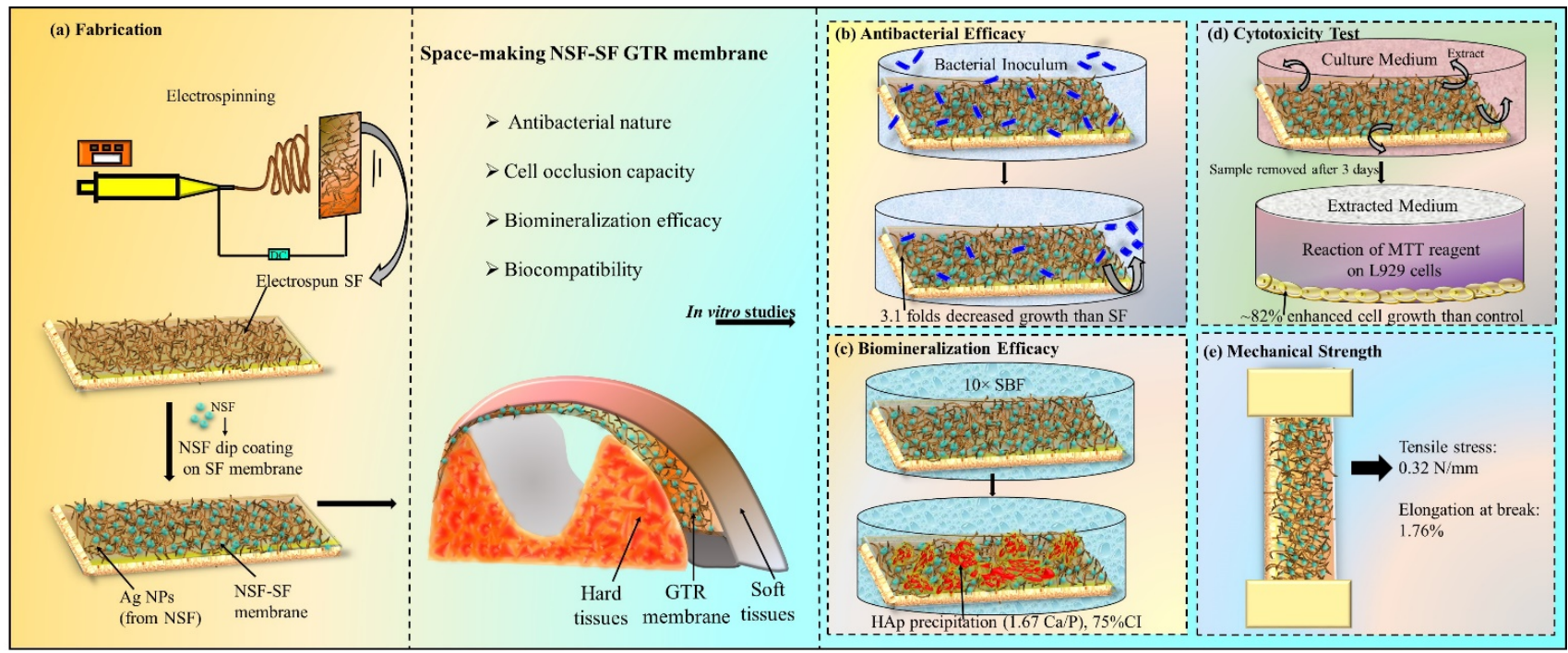

Scheme 1. Representation of the GTR membrane at the affected area, (a) its fabrication, in vitro properties studied as (b) antibacterial, (c) biomineralization, and (d) biocompatibility efficacy, and (e) mechanical strength test.

\section{Conclusions}

The NSF/SDF-coated electrospun silk fibroin membranes were assessed for their biological properties in GTR applications. The biomineralization process of the SF-based samples demonstrated apatite precipitation. The antibacterial efficacy against P.gingivalis concluded the bactericidal nature of all the silver-containing compounds when compared to silk fibroin alone, with the NSF/SDF-coated samples as the most efficient amongst all samples. The SEM-EDS analysis depicted $\mathrm{Ca} / \mathrm{P}$ precipitation on NSF-SF and SF samples. While the detailed surface analysis by FTIR-ATR spectroscopy portrayed the hydroxyapatite deposition on all the samples, as seen by its corresponding peaks. The NSF-SF membranes depicted the highest estimated CI, suggesting excellent bioactivity. Moreover, the tensile strength of the NSF-SF samples was found to be the highest. Therefore, this study corroborates the potent bioactive and antibacterial action of the novel NSF-coated silk fibroin materials as GTR membranes.

Supplementary Materials: The following are available online at https:/ /www.mdpi.com/article/10 .3390/ polym13162659/s1. Figure S1: FTIR-ATR spectra of pure SF-based samples, without biomineralization. Table S1: The $\beta$-sheet/random coil ratio of pure non-biomineralized samples.

Author Contributions: Conceptualization, J.-C.Y., A.P. and N.-C.T.; Methodology, J.-C.Y., A.P., W.F.B., T.-I.Y., I.-W.C., C.-S.H., A.K.; Validation, J.-C.Y., A.P., N.-C.T.; Draft Preparation and Editing, J.-C.Y. and A.P.; Visualization, J.-C.Y. and A.P.; Supervision, J.-C.Y.; Project Administration, J.-C.Y.; Funding Acquisition, J.-C.Y., N.-C.T. and T.-S.Y. All authors have read and agreed to the published version of the manuscript.

Funding: Support for this work was provided by the Ministry of Science and Technology (MOST), Taiwan under the research grant MOST 109-2224-E-038-002. The APC was funded by MOST.

Institutional Review Board Statement: Not applicable.

Informed Consent Statement: Not applicable.

Data Availability Statement: Not applicable.

Conflicts of Interest: The authors declare no conflict of interest. 


\section{References}

1. Rajeshwaran, N.; Gajendran, P. Current trends in antibiotic prescription for various periodontal flap surgical procedure-A hospital based analysis. Eur. J. Mol. 2020, 7, 1427-1439.

2. Newman, M.G.; Takei, H.; Klokkevold, P.R.; Carranza, F.A. Carranza's Clinical Periodontology; Elsevier Health Sciences: Amsterdam, The Netherlands, 2011.

3. Rakhmatia, Y.D.; Ayukawa, Y.; Furuhashi, A.; Koyano, K. Current barrier membranes: Titanium mesh and other membranes for guided bone regeneration in dental applications. J. Prosthodont. Res. 2013, 57, 3-14. [CrossRef] [PubMed]

4. Lee, S.-W.; Kim, S.-G. Membranes for the guided bone regeneration. Maxillofac. Plast. Reconstr. Surg. 2014, 36, 239. [CrossRef] [PubMed]

5. Bottino, M.C.; Thomas, V.; Schmidt, G.; Vohra, Y.K.; Chu, T.-M.G.; Kowolik, M.J.; Janowski, G.M. Recent advances in the development of GTR/GBR membranes for periodontal regeneration-A materials perspective. Dent. Mater. 2012, 28, 703-721. [CrossRef] [PubMed]

6. Elgali, I.; Omar, O.; Dahlin, C.; Thomsen, P. Guided bone regeneration: Materials and biological mechanisms revisited. Eur. J. Oral Sci. 2017, 125, 315-337. [CrossRef] [PubMed]

7. Kim, K.-H.; Jeong, L.; Park, H.-N.; Shin, S.-Y.; Park, W.H.; Lee, S.-C.; Kim, T.-I.; Park, Y.-J.; Seol, Y.-J.; Lee, Y.-M.; et al. Biological efficacy of silk fibroin nanofiber membranes for guided bone regeneration. J. Biotechnol. 2005, 120, 327-339. [CrossRef]

8. Türkkan, S.; Pazarçeviren, A.E.; Keskin, D.; Machin, N.E.; Duygulu, Ö.; Tezcaner, A. Nanosized CaP-silk fibroin-PCL-PEGPCL/PCL based bilayer membranes for guided bone regeneration. Mater. Sci. Eng. C 2017, 80, 484-493. [CrossRef]

9. Zhang, J.-G.; Mo, X.-M. Current research on electrospinning of silk fibroin and its blends with natural and synthetic biodegradable polymers. Front. Mater. Sci. 2013, 7, 129-142. [CrossRef]

10. Jin, H.-J.; Fridrikh, S.V.; Rutledge, G.C.; Kaplan, D.L. Electrospinning bombyx mori silk with poly (ethylene oxide). Biomacromolecules 2002, 3, 1233-1239. [CrossRef]

11. Serôdio, R.; Schickert, S.L.; Costa-Pinto, A.R.; Dias, J.R.; Granja, P.L.; Yang, F.; Oliveira, A.L. Ultrasound sonication prior to electrospinning tailors silk fibroin/PEO membranes for periodontal regeneration. Mater. Sci. Eng. C 2019, 98, 969-981. [CrossRef]

12. Jabbari, F.; Hesaraki, S.; Houshmand, B. The physical, mechanical, and biological properties of silk fibroin/chitosan/reduced graphene oxide composite membranes for guided bone regeneration. J. Biomater. Sci. Polym. Ed. 2019, 30, 1779-1802. [CrossRef] [PubMed]

13. Wang, S.-D.; Ma, Q.; Wang, K.; Chen, H.-W. Improving antibacterial activity and biocompatibility of bioinspired electrospinning silk fibroin nanofibers modified by graphene oxide. ACS Omega 2018, 3, 406-413. [CrossRef] [PubMed]

14. Calamak, S.; Aksoy, E.A.; Ertas, N.; Erdogdu, C.; Sagıroglu, M.; Ulubayram, K. Ag/silk fibroin nanofibers: Effect of fibroin morphology on $\mathrm{Ag}^{+}$release and antibacterial activity. Eur. Polym. J. 2015, 67, 99-112. [CrossRef]

15. Zhang, X.; Jia, C.; Qiao, X.; Liu, T.; Sun, K. Silk fibroin microfibers and chitosan modified poly (glycerol sebacate) composite scaffolds for skin tissue engineering. Polym. Test. 2017, 62, 88-95. [CrossRef]

16. $\mathrm{Hu}, \mathrm{X} . ; \mathrm{Li}$ J.; Bai, Y. Fabrication of high strength graphene/regenerated silk fibroin composite fibers by wet spinning. Mater. Lett. 2017, 194, 224-226. [CrossRef]

17. Jin, S.-H.; Kweon, H.; Park, J.-B.; Kim, C.-H. The effects of tetracycline-loaded silk fibroin membrane on proliferation and osteogenic potential of mesenchymal stem cells. J. Surg. Res. 2014, 192, e1-e9. [CrossRef]

18. AI, V.S.; Ilyina, A.; EP, S.C. Etiology and microbiology of periodontal diseases: A review. Afr. J. Microbiol. Res. 2015, 9, $2300-2306$.

19. Socransky, S.S. Dental biofilms: Difficult therapeutic targets. Periodontol 2002, 28, 12-55. [CrossRef]

20. Cortellini, P. Reconstructive periodontal surgery: A challenge for modern periodontology. Int. Dent. J. 2006, 56, 250-255. [CrossRef] [PubMed]

21. Rossa, M.; Lima, L.; Pustiglioni, F.; Hespanhol, A.; Kon, S.; Grigolli, J.F.; Novo, N. SEM analyses of bacterial contamination of e-PTFE membranes and GTR clinical results. J. Int. Acad. Periodontol. 2006, 8, 115-124. [PubMed]

22. Hung, S.L.; Lin, Y.W.; Wang, Y.H.; Chen, Y.T.; Su, C.Y.; Ling, L.J. Permeability of streptococcus mutans and actinobacillus actinomycetemcomitans through guided tissue regeneration membranes and their effects on attachment of periodontal ligament cells. J. Periodontol. 2002, 73, 843-851. [CrossRef]

23. Cheng, C.-F.; Wu, K.-M.; Chen, Y.-T.; Hung, S.-L. Bacterial adhesion to antibiotic-loaded guided tissue regeneration membranes-A scanning electron microscopy study. J. Formos. Med. Assoc. 2015, 114, 35-45. [CrossRef]

24. Chen, P.; Wu, Z.; Leung, A.; Chen, X.; Landao-Bassonga, E.; Gao, J.; Chen, L.; Zheng, M.; Yao, F.; Yang, H. Fabrication of a silver nanoparticle-coated collagen membrane with anti-bacterial and anti-inflammatory activities for guided bone regeneration. Biomed. Mater. 2018, 13, 065014. [CrossRef]

25. Pinto, J.; Magrì, D.; Valentini, P.; Palazon, F.; Heredia-Guerrero, J.A.; Lauciello, S.; Barroso-Solares, S.; Ceseracciu, L.; Pompa, P.P.; Athanassiou, A. Antibacterial melamine foams decorated with in situ synthesized silver nanoparticles. ACS Appl. Mater. Interfaces 2018, 10, 16095-16104. [CrossRef] [PubMed]

26. Kim, K.-J.; Sung, W.S.; Moon, S.-K.; Choi, J.-S.; Kim, J.G.; Lee, D.G. Antifungal effect of silver nanoparticles on dermatophytes. J. Microbiol. Biotechnol. 2008, 18, 1482-1484. [PubMed]

27. Sibbald, R.G.; Contreras-Ruiz, J.; Coutts, P.; Fierheller, M.; Rothman, A.; Woo, K. Bacteriology, inflammation, and healing: A study of nanocrystalline silver dressings in chronic venous leg ulcers. Adv. Skin Wound Care 2007, 20, 549-558. [CrossRef] 
28. Wang, J.; Zhan, L.; Zhang, X.; Wu, R.; Liao, L.; Wei, J. Silver Nanoparticles Coated Poly (L-Lactide) Electrospun Membrane for Implant Associated Infections Prevention. Front. Pharmacol. 2020, 11, 431. [CrossRef] [PubMed]

29. Rani, S.; Chandra, R.V.; Reddy, A.; Reddy, B.; Nagarajan, S.; Naveen, A. Evaluation of the antibacterial effect of silver nanoparticles on guided tissue regeneration membrane colonization-An in vitro study. J. Int. Acad. Periodontol. 2015, 17, 66-76.

30. Targino, A.G.R.; Flores, M.A.P.; dos Santos Junior, V.E.; Bezerra, F.d.G.B.; de Luna Freire, H.; Galembeck, A.; Rosenblatt, A. An innovative approach to treating dental decay in children. A new anti-caries agent. J. Mater. Sci. Mater. Med. 2014, 25, $2041-2047$. [CrossRef] [PubMed]

31. Mei, M.L.; Chu, C.H.; Low, K.H.; Che, C.M.; Lo, E.C. Caries arresting effect of silver diamine fluoride on dentine carious lesion with S. mutans and L. acidophilus dual-species cariogenic biofilm. Med. Oral Patol. Oral Cir. Bucal 2013, 18, e824. [CrossRef]

32. e Silva, A.V.C.; Teixeira, J.A.; Mota, C.C.; Lins, E.C.C.C.; de Melo Júnior, P.C.; de Souza Lima, M.G.; Arnaud, M.; Galembeck, A.; Gadelha, A.T.; Pereira, J.R.D. In vitro morphological, optical and microbiological evaluation of nanosilver fluoride in the remineralization of deciduous teeth enamel. Nanotechnol. Rev. 2018, 7, 509-520. [CrossRef]

33. Bottino, M.C.; Thomas, V.; Janowski, G.M. A novel spatially designed and functionally graded electrospun membrane for periodontal regeneration. Acta Biomater. 2011, 7, 216-224. [CrossRef] [PubMed]

34. Block, M.S.; Finger, I.; Lytle, R. Human mineralized bone in extraction sites before implant placement: Preliminary results. J. Am. Dent. Assoc. 2002, 133, 1631-1638. [CrossRef]

35. Jacob, S.; Amudha, D. Guided tissue regeneration: A review. J. Dent. Health Oral Disord. Ther. 2017, 6, 00197. [CrossRef]

36. Chen, C.-C.; Lee, S.-Y.; Teng, N.-C.; Hu, H.-T.; Huang, P.-C.; Yang, J.-C. In vitro and in vivo studies of hydrophilic electrospun PLA95/ $\beta$-TCP membranes for Guided Tissue Regeneration (GTR) applications. Nanomaterials 2019, 9, 599. [CrossRef] [PubMed]

37. Soekanto, S.A.; Marpaung, L.J.; Djais, A.A.; Rina, R. Efficacy of propolis fluoride and nano silver fluoride for inhibition of streptococcus mutans and enterococcus faecalis biofilm formation. Int. J. App. Pharm. 2017, 9, 51-54. [CrossRef]

38. Tas, A.C.; Bhaduri, S.B. Rapid coating of Ti6Al4V at room temperature with a calcium phosphate solution similar to $10 \times$ simulated body fluid. J. Mat. Res. 2004, 19, 2742-2749. [CrossRef]

39. Lussi, A.; Schlüter, N.; Rakhmatullina, E.; Ganss, C. Dental erosion-an overview with emphasis on chemical and histopathological aspects. Caries Res. 2011, 45, 2-12. [CrossRef] [PubMed]

40. Sawhney, A.; Condon, B.; Reynolds, M.; Slopek, R.; Hui, D. Advent of greige cotton non-wovens made using a hydro-entanglement process. Text. Res. J. 2010, 80, 1540-1549. [CrossRef]

41. Kumar, M.N.R. A review of chitin and chitosan applications. React. Funct. Polym. 2000, 46, 1-27. [CrossRef]

42. Aldemir Dikici, B.; Dikici, S.; Reilly, G.C.; MacNeil, S.; Claeyssens, F. A novel bilayer polycaprolactone membrane for guided bone regeneration: Combining electrospinning and emulsion templating. Materials 2019, 12, 2643. [CrossRef]

43. Khayati, G.; Janghorban, K. The nanostructure evolution of Ag powder synthesized by high energy ball milling. Adv. Powder Technol. 2012, 23, 393-397. [CrossRef]

44. Burgess, J.; Vaghela, P. Silver diamine fluoride: A successful anticarious solution with limits. Adv. Dent. Res. 2018, 29, 131-134. [CrossRef]

45. Rams, T.E.; Sautter, J.D.; Ramírez-Martínez, G.J.; Whitaker, E.J. Antimicrobial activity of silver diamine fluoride on human periodontitis microbiota. Gen. Dent. 2020, 68, 24-28.

46. Pandey, A.; Midha, S.; Sharma, R.K.; Maurya, R.; Nigam, V.K.; Ghosh, S.; Balani, K. Antioxidant and antibacterial hydroxyapatitebased biocomposite for orthopedic applications. Mater. Sci. Eng. C 2018, 88, 13-24. [CrossRef]

47. Pandey, A.; Patel, A.K.; Kumar, V.; Sharma, R.K.; Kanhed, S.; Nigam, V.K.; Keshri, A.; Agarwal, A.; Balani, K. Enhanced tribological and bacterial resistance of carbon nanotube with ceria-and silver-incorporated hydroxyapatite biocoating. Nanomaterials 2018, 8 , 363. [CrossRef]

48. Tian, X.; Jiang, X.; Welch, C.; Croley, T.R.; Wong, T.-Y.; Chen, C.; Fan, S.; Chong, Y.; Li, R.; Ge, C. Bactericidal effects of silver nanoparticles on lactobacilli and the underlying mechanism. ACS Appl. Mater. Interfaces 2018, 10, 8443-8450. [CrossRef] [PubMed]

49. Chi, M.; Qi, M.; Wang, P.; Weir, M.D.; Melo, M.A.; Sun, X.; Dong, B.; Li, C.; Wu, J.; Wang, L. Novel bioactive and therapeutic dental polymeric materials to inhibit periodontal pathogens and biofilms. Int. J. Mol. Sci. 2019, 20, 278. [CrossRef] [PubMed]

50. Lee, D.; Lee, S.J.; Moon, J.-H.; Kim, J.H.; Heo, D.N.; Bang, J.B.; Lim, H.-N.; Kwon, I.K. Preparation of antibacterial chitosan membranes containing silver nanoparticles for dental barrier membrane applications. J. Ind. Eng. Chem. 2018, 66, 196-202. [CrossRef]

51. Yin, I.X.; Zhang, J.; Zhao, I.S.; Mei, M.L.; Li, Q.; Chu, C.H. The antibacterial mechanism of silver nanoparticles and its application in dentistry. Int. J. Nanomed. 2020, 15, 2555. [CrossRef]

52. Zhao, I.S.; Gao, S.S.; Hiraishi, N.; Burrow, M.F.; Duangthip, D.; Mei, M.L.; Lo, E.C.-M.; Chu, C.-H. Mechanisms of silver diamine fluoride on arresting caries: A literature review. Int. Dent. J. 2018, 68, 67-76. [CrossRef]

53. Ghorbani, F.; Zamanian, A.; Behnamghader, A.; Joupari, M.D. Microwave-induced rapid formation of biomimetic hydroxyapatite coating on gelatin-siloxane hybrid microspheres in 10X-SBF solution. e-Polymers 2018, 18, 247-255. [CrossRef]

54. Mei, M.L.; Ito, L.; Cao, Y.; Li, Q.; Lo, E.C.; Chu, C. Inhibitory effect of silver diamine fluoride on dentine demineralisation and collagen degradation. J. Dent. 2013, 41, 809-817. [CrossRef] [PubMed]

55. Lou, Y.; Botelho, M.; Darvell, B. Reaction of silver diamine fluoride with hydroxyapatite and protein. J. Dent. 2011, 39, 612-618. [CrossRef] 
56. George, A.; Veis, A. Phosphorylated proteins and control over apatite nucleation, crystal growth, and inhibition. Chem. Rev. 2008, 108, 4670-4693. [CrossRef] [PubMed]

57. Song, J.; Malathong, V.; Bertozzi, C.R. Mineralization of synthetic polymer scaffolds: A bottom-up approach for the development of artificial bone. J. Am. Chem. Soc. 2005, 127, 3366-3372. [CrossRef]

58. Mavis, B.; Demirtaş, T.T.; Gümüşderelioğlu, M.; Gündüz, G.; Çolak, Ü. Synthesis, characterization and osteoblastic activity of polycaprolactone nanofibers coated with biomimetic calcium phosphate. Acta Biomater. 2009, 5, 3098-3111. [CrossRef]

59. Drouet, C. Apatite formation: Why it may not work as planned, and how to conclusively identify apatite compounds. BioMed Res. Int. 2013, 2013, 490946. [CrossRef]

60. Wu, J.; Cao, L.; Liu, Y.; Zheng, A.; Jiao, D.; Zeng, D.; Wang, X.; Kaplan, D.L.; Jiang, X. Functionalization of silk fibroin electrospun scaffolds via BMSC affinity peptide grafting through oxidative self-polymerization of dopamine for bone regeneration. ACS Appl. Mater. Interfaces 2019, 11, 8878-8895. [CrossRef]

61. Sailaja, G.; Ramesh, P.; Vellappally, S.; Anil, S.; Varma, H. Biomimetic approaches with smart interfaces for bone regeneration. J. Biomed. Sci. 2016, 23, 1-13. [CrossRef]

62. Yang, F.; Both, S.K.; Yang, X.; Walboomers, X.F.; Jansen, J.A. Development of an electrospun nano-apatite/PCL composite membrane for GTR/GBR application. Acta Biomater. 2009, 5, 3295-3304. [CrossRef] [PubMed]

63. Rnjak-Kovacina, J.; Wray, L.S.; Burke, K.A.; Torregrosa, T.; Golinski, J.M.; Huang, W.; Kaplan, D.L. Lyophilized silk sponges: A versatile biomaterial platform for soft tissue engineering. ACS Biomater. Sci. Eng. 2015, 1, 260-270. [CrossRef] [PubMed]

64. Riccio, M.; Maraldi, T.; Pisciotta, A.; La Sala, G.B.; Ferrari, A.; Bruzzesi, G.; Motta, A.; Migliaresi, C.; De Pol, A. Fibroin scaffold repairs critical-size bone defects in vivo supported by human amniotic fluid and dental pulp stem cells. Tissue Eng. Part A 2012, 18, 1006-1013. [CrossRef] [PubMed]

65. Cai, Y.; Guo, J.; Chen, C.; Yao, C.; Chung, S.-M.; Yao, J.; Lee, I.-S.; Kong, X. Silk fibroin membrane used for guided bone tissue regeneration. Mat. Sci. Eng. C 2017, 70, 148-154. [CrossRef]

66. Xue, J.; He, M.; Liang, Y.; Crawford, A.; Coates, P.; Chen, D.; Shi, R.; Zhang, L. Fabrication and evaluation of electrospun PCL-gelatin micro-/nanofiber membranes for anti-infective GTR implants. J. Mater. Chem. B 2014, 2, 6867-6877. [CrossRef]

67. Fancher, M.E.; Fournier, S.; Townsend, J.; Lallier, T.E. Cytotoxic effects of silver diamine fluoride. Am. J. Dent. 2019, $32,152-156$.

68. Mejía-Suaza, M.L.; Moncada, M.E.; Ossa-Orozco, C.P. Characterization of Electrospun Silk Fibroin Scaffolds for Bone Tissue Engineering: A Review. TecnoLógicas 2020, 23, 228-246. [CrossRef]

69. Augustine, R.; Kalarikkal, N.; Thomas, S. Electrospun PCL membranes incorporated with biosynthesized silver nanoparticles as antibacterial wound dressings. Appl. Nanosci. 2016, 6, 337-344. [CrossRef] 